\title{
Prevalence of Intestinal Parasitosis Among School Children in Baglung District of Western Nepal
}

\author{
Shrestha $A,{ }^{1}$ KC Narayan, ${ }^{2}$ Sharma $R^{2}$
}

${ }^{1}$ Department of Microbiology, Tribhuwan University

${ }^{2}$ Institute of Medicine, Maharajgunj Campus, Tribhuwan Univeristy

\section{Corresponding Author \\ Anil Shrestha \\ Department of Microbiology, \\ Tribhuwan University. \\ Email: anilsth@gmail.com}

\section{Citation}

Shrestha A, KC Narayan, Sharma R.Prevalence of Intestinal Parasitosis among School Children in Baglung District of Western Nepal. Kathmandu Univ Med J 2012;37(1):3-6.

\section{ABSTRACT \\ Background}

This study was carried out to estimate the prevalence of intestinal parasites among school-going children of the Baglung municipality from December 2010 to January 2011.

\section{Objective}

To find out prevalence of parasitosis among school aged children and to make necessary recommendations for preventive measures.

\section{Method}

A total of 260 stool samples were collected. A structured questionnaire was used to collect data on predisposing factors. Nails were observed without prior information to the subjects so as to find their hygienic practice. The stool samples were examined by direct wet mount and formal ether concentration technique.

\section{Results}

The total prevalence of the intestinal parasitosis was found to be $21.05 \%$. The prevalence for individual parasites was as follows: Entamoeba histolytica (9.23\%), Giardia lamblia (5.76\%), Trichuris trichuria (5\%), Ancylostoma duodenale (2.65\%) and Ascaris lumbricoides (2.3\%). Nail hygiene and level of education were significantly associated with intestinal parasitosis. The gender and age of the children, sanitary habits including toilet use, hand washing practice, and the use of the antihelminthic drug (albendazole) were not significantly associated with intestinal parasitosis. Higher prevalence was seen in boys, children belonging to age group 10-14 years, lower secondary students, among those who reported gastrointestinal problems within last six months, children from agriculture-based families and children with untrimmed nail.

\section{Conclusion}

Major contributors for the prevalence of parasites were found to be poor personal hygiene and educational level of the children. Health education and mass treatment are recommended as a preventive measures.

\section{KEY WORDS}

Hygiene, parasites, prevalence, school children

\section{INTRODUCTION}

Intestinal parasitic infection is one of the major health problems in developing countries. This is highly debilitating rather than deadly worm-induced diseases like filariasis and taeniasis. Soil-transmitted helminthes (STH) are particularly pernicious and are among the ten most common infections in the world. ${ }^{1}$ The World Health Organization estimates that over 270 million pre-school children and over 600 million of school children are living in areas where the parasites are intensively transmitted and are in need of treatment and preventive interventions. ${ }^{2}$ At least 750 million episodes of diarrhoea occur per year in developing countries that results in five million deaths. ${ }^{3}$ It is noteworthy to mention 
that intestinal parasitic infections are distributed virtually throughout the world with high prevalence rates in underdeveloped regions. Similarly, amoebiasis, ascariasis, ancylostomiasis and trichuriasis are common among the top ten infections in the world. ${ }^{4-6}$

The problem of STH is predominant among the school children, and is often associated with poor growth, reduced physical activity, impaired cognitive function, and learning ability. ${ }^{7}$ Helminthic infections are also associated with nutritional deficiencies, particularly of iron and vitamin A, with improvements in iron status and increments in vitamin-A absorption seen after deworming. ${ }^{8}$

An intestinal worm has been one of the major causes for the visit to health care facilities in the country. It was the number one cause of morbidity for the healthcare visit in the year2008/2009. ${ }^{9}$ This study was done to find out the prevalence of the intestinal parasitosis in the school going children in the western part of Nepal.

\section{METHODS}

This cross-sectional study was carried out from December 2010 to January 2011. The study sample consisted of 350 students of the school however only 260(66\%) participated voluntarily. All subjects were offered equal opportunity to participate in the study. Information regarding the study protocol was disseminated to the school authorities prior to the commencement of the study. Verbal consent was also taken from the parents. A total of 102 girls (39.23\%) and 158 boys $(60.77 \%)$ participated voluntarily in this study. Data regarding predisposing factors were collected using a structured questionnaire and children's nails were observed without prior notification to find out their nail sanitation. Plastic containers with identification numbers and names were distributed to all the children for collecting stool samples. Information about name, gender, age, school grade, dietary habit, water source, number of family members, major occupation in the family, sanitary habits and the result of stool examination for each child was recorded on the stool examination forms. Laboratory analyses of faecal samples were carried out by formal ether sedimentation technique. ${ }^{10}$ Subjects were provided with written notification of test results. $\chi 2$ - test for test of independence was applied to study the association between prevalence of intestinal parasites and the demographic factors. $P$ value $<0.05$ was considered as statistically significant.

\section{RESULTS}

Intestinal parasites were detected in $55(n=260)$ school aged children (21.05\%) (Table 1).At least one intestinal protozoan was found in stool samples from 26 children $(10 \%)$ and at least one helminthes was found in 19 stool samples (7.3\%) (Table 1).
Table.1 Prevalence of intestinal parasitic infections.

\begin{tabular}{|c|c|c|c|}
\hline \multicolumn{2}{|c|}{ Types of Infection } & \multirow{2}{*}{$\begin{array}{c}\text { Total }(n=260) \\
45\end{array}$} & \multirow{2}{*}{$\begin{array}{r}\% \\
17.3\end{array}$} \\
\hline Sin & & & \\
\hline - & Protozoa & 26 & 10 \\
\hline - & Helminths & 19 & 7.3 \\
\hline & & 10 & 3.75 \\
\hline • & Protozoa+Protozoa & 3 & 1.15 \\
\hline • & Protozoa+Helminth & 7 & 2.6 \\
\hline Tot & & 55 & 21.05 \\
\hline
\end{tabular}

Mixed infection with either protozoan and protozoan or protozoan and helminth was found in 10 stool samples (3.75\%) (Table 1). Among all protozoal infections, Entamoeba histolytica was found to be predominant (9.23\%) (Table 2) followed by Giardia lamblia (5.76\%) (Table 2). Among the helminth infestations, Trichuris trichuria was the commonest (5\%) (Table 2) accompanied by Ancylostoma duodenale (2.65\%) (Table 2) and Ascaris lumbricoides (2.3\%) (Table 2).

Table. 2 Frequency of parasites detected.

\begin{tabular}{|ccl|}
\hline Types of Parasite & Total $(\mathbf{n = 2 6 0})$ & $\%$ \\
\hline Trichuris trichuria & 13 & 5 \\
\hline Ancylostoma duodenale & 7 & 2.65 \\
\hline Ascaris lumbricoides & 6 & 2.3 \\
\hline Total helminthes & 26 & 10 \\
\hline Entamoeba histolytica & 24 & 9.23 \\
\hline Giardia lamblia & 15 & 5.76 \\
\hline Entamoeba coli & 1 & 0.3 \\
\hline Total Protozoa & 40 & 15.38 \\
\hline
\end{tabular}

There was slightly higher prevalence of intestinal parasites seen in males $(22.78 \%$ ) (Table 3 ) as compared to female children (19.38\%) (Table: 3 ) ( $p>0.05)$ There was higher prevalence was seen in children belonging to age group $10-14$ years $(23.33 \%) \quad(p<0.05) \quad($ Table 3$)$ followed by lower secondary children (Classes 5-8). Those students who reported gastrointestinal complaints were found to have higher rate of infection from the intestinal parasites (23.45\%) (Table 3). Families with agriculture as a major occupation had children with higher percentage of infections (29.41\%) in comparison to other occupations (Table 3) ( $>0.05)$. Children who had not trimmed their nails at the time of observation had higher prevalence of the infections associated with intestinal parasites (33.33\%) (Table 3$)(p<0.05)$ as compared to those who had trimmed their nails. 
Table. 3 Parasitic prevalence gender-wise.

\begin{tabular}{|l|l|l|l|l|}
\hline Gender & Total & Positive & $\%$ & \\
Male & 158 & 36 & 22.78 & $\mathrm{P}>0.05$ \\
\hline Female & 102 & 19 & 19.38 & \\
\hline Total & 260 & 55 & 21.15 & \\
\hline Class & & & & \\
\hline$\leq 4$ (primary) & 167 & 28 & 16.77 & $\mathrm{P}<0.05$ \\
\hline 5-8 (lower secondary) & 80 & 26 & 32.5 & \\
\hline 9-10 (secondary) & 13 & 1 & 7.69 & \\
\hline Total & 260 & 55 & 21.15 & \\
\hline Gl symptoms & & & & \\
\hline Yes & 162 & 38 & 23.45 & $\mathrm{P}>0.05$ \\
\hline No & 98 & 17 & 17.34 & \\
\hline Total & 260 & 55 & 21.15 & \\
\hline Major occupation in the family & & & & \\
\hline Agriculture & 17 & 5 & 29.41 & $\mathrm{P}>0.05$ \\
\hline Business & 53 & 14 & 26.41 & \\
\hline Service & 113 & 24 & 21.23 & \\
\hline Abroad & 44 & 7 & 15.90 & \\
\hline Others & 33 & 5 & 15.15 & \\
\hline Total & 260 & 55 & 21.15 & \\
\hline Nail trimming & & & & \\
\hline Done & 191 & 32 & 16.75 & $\mathrm{P}<0.05$ \\
\hline Not done & 61 & 23 & 33.33 & \\
\hline Total & 260 & 55 & 21.15 & \\
\hline & & & & \\
\hline
\end{tabular}

\section{DISCUSSION}

Statistically significant result was detected between observed nail trimming status and prevalence of parasites according to the class level. There was no statistical difference in the prevalence of intestinal parasites with the gender and age of the children, water source and type of water used for drinking purpose, dietary habits, and major occupation in the family, sanitary habits including toilet use and hand washing habits before meal and after toilet use. Similarly, prevalence was not found to be related to the use of the antihelminthic drug (Albendazole) within the last six months. The prevalence of the intestinal parasites, both the protozoa and the helminthes found in this study was lower $(21 \%)$ in comparison to other studies which may be due to the regular biannual deworming program of the Government of Nepal along with Vitamin A supplementation. In Nepal, the highest prevalence of the intestinal parasites was found in the study done in rural and urban settings of Lalitpur District which is $81.94 \% .{ }^{11}$ This is because this study was done around a decade ago and the study group contained a rural population who lacked access to proper health care services. However, the results are comparable with the study done in eastern part of Nepal which is $22.5 \% .^{12}$ Higher prevalence of parasitic infection was seen in those children who had not trimmed their nails during our observation $33.33 \%$ in comparison to $16.75 \%$ seen in children who had trimmed their nails). Similar findings were also reported elsewhere. ${ }^{13,14}$ The reason may be attributed to habit of suckling of fingers, unhygienic playing fields and eating with unwashed hands. The study also found higher prevalence of intestinal parasites infection in the children who reported the incidence of diarrhea within the one month period prior to the study. This is in accordance to other studies carried out in Nepal where protozoal infections were related to the history of diarrhea incidence, the cause being protozoa behind the cause of diarrhea. ${ }^{15,16}$ Students of lower secondary level i.e. class 5 to $8(32.5 \%)$ were found to be infected more as compared to primary i.e. 1 to $4(16.77 \%$ ) and secondary level i.e. 9 and $10(7.69 \%)$. It may be due to the fact that primary school children usually are under the direct observation of their parents and the secondary school children can understand the values of the proper hygiene but lower secondary level children are in their transition phase and are seldom under the control of their parents regarding dietary habits and usually lack the education regarding healthy dietary habits. The study was limited to a single school. Though there was inclusion of the students from different backgrounds, race and economic status, we did not take into consideration of this data during the study. Most of the students who took part in the study were from same geographical background and the study lacks relation of the geographical location with the prevalence of the intestinal parasitosis.

\section{CONCLUSION}

This study has shown that nail hygiene and educational level are closely associated with the prevalence of intestinal infections. There is a need for intensive and habitual health education for behavioural changes related to personal hygiene and mass treatment for the effective control of intestinal parasitic infections in the concerned area. The prevention and control of parasitic diseases depend upon economic development as well consequent improvements in personal hygiene and sanitation, water supplies, health education and socio-economic status. In order to obtain maximum benefits, further epidemiological studies focusing on control of parasitic diseases require to be undertaken in a coordinated manner.

\section{ACKNOWLEDGEMENT}

We are grateful to Mr. Nirmal Sapkota, the campus chief of Dhawalagiri Prabidhik Shikshya Pratisthan for providing laboratory facility during the study. We also acknowledge to M r. Gurudutta Sharma, Mr. Safal Sharma, Ms. Anita Rajbhandari, Ms. Sovita Sharma, Ms. Sneha Sharma, Ms. Laxmi Gharti and Ms. Ganga Thapa for their contribution. 


\section{REFERENCES}

1. WHO. Public health significance of intestinal parasitic infections. Bull World Health Organ 1987; 65(5): 575-588.

2. WHO. Neglected Tropical Diseases - PCT Databank. 2010.

3. Shakya B, Rai SK, Rai G, Shrestha A, Singh A. Study on intestinal infections by parasite and some bacteria among elderly people of Kathmandu valley. Nepal Med Coll J. 2006 Dec; 8(4): 243-247.

4. Rai SK, Gurung CK. Intestinal parasitic infection in high school level students of Birgunj City. J Inst Med 1986; 8: 33-38.

5. Reily C. Gorkha Report, Dooly foundation, Nepal. 1980.

6. Stevez EG, Levine JA and Warren J. Intestinal parasites in a remote village in Nepal. J Clin Microbiol 1983; 17: 160-161.

7. Stephenson LS, Latham MC, Kinoti SN, Kurz KM, Brigham H. Improvement in physical fitness in Kenya schoolboys infected with hookworm, Trichuris trichiura and Ascaris lumbricoides following a single dose of Albendazole. Trans R Soc Trop Med Hyg. 1998; 84: 277282.

8. WHO, UNICEF[Internet]. Prevention and control of schistosomiasis and soil transmitted helminthes. New York:2004. Available from: http://www.who.int/wormcontrol/documents/joint_statements/en/ ppc_unicef_finalreport.pdf.

9. Department of Health Services. Annual Report 2065/2066. 2010:201202
10. WHO Regional Office for South East Asia. Guidelines on Standard Operating Procedure for Microbiology 2006.[cited Aug 2011] Available from: http://www.searo.who.int/en/Section10/Section17/ Section53/Section482_1804.htm.

11. Shrestha B. Intestinal Parasitic Infestation in Healthy School Children of Lalitpur District. JNMA 2001; 41:266-270.

12. Gyawali N, Amatya R, Nepal HP. Intestinal parasitosis in school going children of Dharan municipality, Nepal. Trop Gastroenterol 2009 JulSep; 30(3):145-7.

13. Yodomani B, Sornmani S, Phatihatakorn W, Harinasuta C. Re-infection of Ascariasis after Treatment with Pyrantel Pamoate and the Factors Relating to its active Transmission in a slum in Bangkok. In: Collected papers on the control of soil transmitted helminthiasis. Asian parasite control Organ 1983; 2: 89-103.

14. Ismid Suharijha, Rukmono Bintari. Nail and dust examination for helminthic eggs in orphanages. In: Collected papers on the control of soil transmitted helminthiasis. AsianParasite Control Organ 1983; 6: 59-61.

15. Uga S, Rai SK, Kimura K, Rai G, Kimura D, Wakasugi M et al. Parasites detected form diarrhoeal stool samples collected in Nepal. Southeast Asian J Trop Med Public Health 2004; 35: 19-23.

16. Mukhopadhyay M, Wilson G, Pradhan D, Shivananda PS. Intestinal protozoal infestation profile in persistent diarrhoea in children below age five years in western Nepal. Southeast Asian J Trop Med Public Health 2007; 38: 13-9. 